\title{
MUDANÇAS NO MODELO DE NEGÓCIO E ALINHAMENTO DA ESTRUTURA ORGANIZACIONAL
}

CHANGES IN THE BUSINESS MODEL AND ALIGNMENT OF THE ORGANIZATIONAL STRUCTURE

\section{José Turíbio Oliveira ${ }^{1}$}

ORCID: http://orcid.org/0000-0002-3281-1428

\section{Sérgio Feliciano Crispim²}

ORCID: http://orcid.org/0000-0002-4060-8315

\section{RESUMO}

O presente artigo explora o alinhamento da estrutura organizacional decorrente de mudanças significativas nos modelos de negócios. Realizou-se estudo de casos múltiplos com três empresas de grande porte visando identificar as mudanças da estrutura para suportar os novos modelos de negócios. Conclui-se que: a) as empresas alteraram significativamente seus modelos de negócios e as estruturas organizacionais passaram por modificações importantes; b) os quatro componentes das estruturas organizacionais (posições, superestrutura, vínculos laterais e sistema de decisão) foram alterados; c) a adoção das novas estruturas ocorreu simultaneamente às alterações nos modelos de negócios; d) a estrutura Divisionada com serviços compartilhados foi adotada pelas empresas; e) as empresas relataram que se as estruturas organizacionais não tivessem sido alteradas, os modelos de negócios significativamente alterados não teriam sucesso; f) as novas estruturas adotaram delegação de poder, gerando proximidade com clientes e desenvolvimento de produtos específicos, além de sentimento de maior envolvimento das pessoas.

Palavras-chave: Estrutura Organizacional. Modelo de Negócio. Estrutura Divisionada. Parâmetros de Design.

\section{ABSTRACT}

This article explores the alignment of the organizational structure resulting from significant changes in business models. A multi-case study was carried out with three large companies aiming to identify the structure changes to support the new business models. We conclude that: a) companies have significantly changed their business models and organizational structures have undergone important changes; b) the four components of organizational structures (positions, superstructure, lateral links and decision system) have been changed; c) the adoption of the new structures occurred simultaneously with changes in business models; d) the division structure with shared services was adopted by the companies; e) companies reported that if organizational structures had not been changed, significantly altered business models would not succeed; f) the new structures adopted a delegation of power, generating proximity to customers and development of specific products, as well as a feeling of greater involvement of people.

Keywords: Organizational structure. Business model. Division Structure. Design Parameters. 


\section{INTRODUÇÃO}

Em um ambiente competitivo extremamente dinâmico e desafiador as empresas precisam promover mudanças em seus modelos de negócios e, neste contexto, Ribeiro (2009) considera que as estruturas organizacionais cumprem um papel muito importante e tendem a tornar-se mais flexíveis, visando o alinhamento aos modelos de negócios. Segundo Amit e Zott (2012) o modelo de negócio e a estratégia afetam diretamente a performance empresarial, e a estrutura organizacional constitui-se em um componente fundamental do modelo operacional dos modelos de negócios, à medida que influencia diretamente o processo de implementação.

Dado esse contexto, esta pesquisa teve como objetivo identificar alterações promovidas na estrutura organizacional de empresas que mudaram significativamente seus modelos de negócios.

\section{REVISÃO DA LITERATURA}

\subsection{MODELO DE NEGÓCIO E MUDANÇA SIGNIFICATIVA}

O termo modelo de negócio tem sido utilizado com crescente frequência no meio empresarial e também no meio acadêmico, sendo que alguns autores afirmam que essa tendência tem sido impulsionada pelo incremento da tecnologia no ambiente de negócios.

Nesse sentido, o incremento do termo após a Interneté enfatizado por Magretta (2002), enquanto Gouveia (2006) relaciona-o às transferências de conhecimentos possibilitadas pelo uso da tecnologia. Osterwalder, Pigneur e Tucci (2005) associam-no ao período de grande valorização das empresas de tecnologia transacionadas na bolsa Nasdaq, nos EUA.

No entanto, a definição de modelo de negócio, proposta por Chesbroug (2012) enfatiza seu uso de maneira ampla, não restrita apenas a empresas de alta tecnologia: "um modelo de negócio descreve a lógica de como uma organização cria, entrega e captura valor (formas econômicas, sociais ou qualquer outro valor)" (CHESBROUG, 2012).

Pesquisas de Osterwalder, Pigneur e Tucci (2005), evidenciam quatro pilares de sustentação para os modelos de negócios: produto, relacionamento com clientes, gestão de infraestrutura e aspectos financeiros. Os referidos autores propõem nove blocos constitutivos para os referidos pilares de sustentação: configuração de valor, proposta de valor, competências essenciais, estrutura de custos, fluxo de receita, relacionamento com parceiros, relacionamento, canal de distribuição e, clientealvo. Em outra obra, dois desses autores mencionam ainda que "as características de um modelo de negócio determinam a estrutura organizacional ideal para sua execução" (OSTERWALDER; PIGNEUR, 2011).

Por outro lado, os mesmos autores enunciam os pontos que devem ser considerados para se avaliar as mudanças nos modelos de negócios das empresas: satisfação de necessidades de mercado até então não atendidas; entrega de novos produtos, serviços ou tecnologias ao mercado; aprimoramento ou transformação de um mercado já existente e, criação de um novo mercado. 


\subsection{ESTRUTURA ORGANIZACIONAL}

\subsubsection{Conceito}

Os estudos das estruturas organizacionais são encontrados desde os primórdios da Administração Científica. Henri Fayol (1978) considerava o que denominava de "duplo organismo, material e social, da empresa", quando se referia à constituição de organização. A Teoria Estruturalista também estudou a concepção das organizações, a partir de um sistema social aberto deliberadamente construído (SILVA, 2001).
Etzioni (1968) menciona a vantagem do elemento concreto que possibilita tornar a teoria mais verificável. Nessa mesma linha de estudo, Biasca apresenta o conceito de estrutura abordando seu aspecto concreto, a saber: " ...estrutura da empresa como os aspectos físicos (instalações, localização, etc.), administrativos (organização, procedimentos, etc.), humanos (cultura), financeiros e legais" (BIASCA, 1995).

De maneira a que se possa melhor compreender as relações da estrutura com os negócios, apresentam-se no Quadro 1 os diversos conceitos e características propostas por diversos autores.

Quadro 1 - Conceitos/características de estrutura organizacional.

\begin{tabular}{|c|c|}
\hline Autor & Conceito/característica de estrutura organizacional \\
\hline Fayol (1978) & Duplo organismo, material e social, da empresa. \\
\hline Motta (1979) & $\begin{array}{l}\text { Tudo o que a análise interna de uma totalidade revela, ou seja, } \\
\text { elementos, suas inter-relações, disposições. }\end{array}$ \\
\hline (1990) Manual de Oslo & Componente que distingue a capacidade inovativa da organização. \\
\hline (1993) Montana; Charnov & $\begin{array}{l}\text { Componentes, considerados como a responsabilidade, a autoridade } \\
\text { e a prestação de contas, que se envolvem em relações primárias. }\end{array}$ \\
\hline Biasca (1995) & $\begin{array}{l}\text { Aspectos físicos (instalações, localização, etc.), administrativos } \\
\text { (organização, procedimentos, etc.), humanos (cultura), financeiros e legais, } \\
\text { cuja mudança exige certo tempo. }\end{array}$ \\
\hline $\begin{array}{l}\text { Vasconcellos; } \\
\text { Hemsley (1997) }\end{array}$ & $\begin{array}{l}\text { Resultado de um processo através do qual a autoridade é distribuída, } \\
\text { as atividades, desde os níveis mais baixos até a mais alta administração, são } \\
\text { especificadas e um sistema de comunicação é delineado permitindo que as } \\
\text { pessoas realizem atividades e exerçam a autoridade que lhes compete para o } \\
\text { atingimento dos objetivos organizacionais. }\end{array}$ \\
\hline Gonçalves (2000) & Fluxo de trabalho em torno de um processo. \\
\hline Mintzberg (2003) & $\begin{array}{l}\text { Soma total das maneiras pelas quais o trabalho é dividido em tarefas } \\
\text { distintas e, depois, como a coordenação é realizada entre essas tarefas. }\end{array}$ \\
\hline Oliveira (2007) & $\begin{array}{l}\text { Disposição de partes em uma organização e as relações mantidas } \\
\text { entre elas. Partes que se materializam em pessoas, cargos, grupos, } \\
\text { departamentos, áreas etc., cada uma com certas atividades específicas, mas } \\
\text { mantendo interações umas com as outras e podendo ser vistas, assim, como } \\
\text { um todo organizacional. }\end{array}$ \\
\hline Carreira (2009) & $\begin{array}{l}\text { Superposição de órgãos, de forma a representar aqueles que têm } \\
\text { maior ou menor autoridade hierárquica em relação aos demais. }\end{array}$ \\
\hline $\begin{array}{l}\text { Burton; Desanctis; } \\
\text { Obel (2010) }\end{array}$ & Configuração de uma empresa. \\
\hline
\end{tabular}




\begin{tabular}{|c|c|}
\hline Autor & Conceito/característica de estrutura organizacional \\
\hline (2011) Madeira; Pereira & $\begin{array}{r}\text { Relações de autoridade e poder, as maneiras como o trabalho } \\
\text { é definido e suas tarefas, as formas de coordenação dessas tarefas, e os } \\
\text { elementos que propiciam consistência e harmonia interna. }\end{array}$ \\
\hline
\end{tabular}

Fonte: Elaborado a partir dos autores mencionados.

Por outro lado, as alterações nos modelos de negócios resultam de esforços ocorridos dentro da organização e que estão ligados à estrutura organizacional (OSTERWALDER; PIGNEUR, 2011). A estrutura atua como impulsionadora da implantação dos novos modelos, sendo motivada por diversos aspectos, sendo eles: a existência de insatisfação com o modelo existente, a necessidade de adaptação do modelo existente ao ambiente em mutação, a necessidade de entrega de novos produtos ou serviços aos clientes e, por último, preparação da organização para o futuro (OSTERWALDER; PIGNEUR, 2011).

\subsubsection{Tipologia das estruturas organizacionais}

Os estudos de Henry Mintzberg (2003) consideram a existência de cinco tipos de estrutura:

- Estrutura Simples: É "baseada na supervisão direta, em que a cúpula estratégica é a parte principal" (MINTZBERG, 2003). São organizações com pouco ou nenhuma estrutura, poucos assessores de apoio, divisão do trabalho não rigorosa, diferenciação mínima entre suas unidades e pequena hierarquia gerencial.

- Burocracia Mecanizada: É a organização “baseada na padronização dos processos de trabalho, em que a tecnoestrutura é a parte principal" (MINTZBERG, 2003). Nesse tipo de organização há "tarefas operacionais rotineiras e altamente especializadas; procedimentos muito formalizados no núcleo operacional; proliferação de normas, regulamentos e comunicação formalizada em toda a organização; grandes unidades no nível operacional; confiança na base funcional para agrupamento das tarefas; poder de tomada de decisão relativamente centralizado; e estrutura administrativa elaborada com nítida distinção entre linha e assessoria" (MINTZBERG, 2003).

- Burocracia Profissional: É "baseada na padronização de habilidades, em que o núcleo operacional é a parte principal" (MINTZBERG, 2003). A estrutura tipo "Burocracia Profissional baseia-se na coordenação da padronização das habilidades e em seus parâmetros de design associados, o treinamento e a doutrinação. Contrata profissionais especializados, devidamente treinados e doutrinados, para o núcleo operacional e, depois, concedeIhes considerável controle sobre seu próprio trabalho" (MINTZBERG, 2003).

- Forma Divisionada: Esse tipo de estrutura é "baseado na padronização dos outputs, em que a linha intermediária é a parte principal" (MINTZBERG, 2003). O autor menciona ainda que essa configuração "confia na 
base de mercado para agrupar as unidades no topo da linha intermediária... As divisões são criadas conforme os mercados a que atendem e, depois, assumem o controle sobre as funções operacionais exigidas para servir a esses mercados" (MINTZBERG, 2003). Nesse tipo de configuração, a unidade central pode prover serviços a todas as unidades (LUNENBURG, 2012).

- Adhocracia: Nesse tipo, a estrutura é "baseada em ajustamento mútuo, em que a assessoria de apoio (às vezes, acompanhada do núcleo operacional) é a parte principal" (MINTZBERG, 2003). Trata-se de "uma estrutura altamente orgânica, com pouca formalização do comportamento; sua especialização do trabalho é altamente horizontalizada, baseada em treinamento formal; tendência a agrupar especialistas das unidades funcionais para propósitos de organização interna divididos em pequenas equipes de projeto, baseadas no mercado, que visam à execução de um trabalho específico; confia nos instrumentos de interligação para encorajar o ajustamento mútuo, mecanismo-chave de coordenação interna e entre as equipes; e adota a descentralização seletiva das equipes localizadas em vários pontos da organização, envolvendo vários grupos formados por gerentes de linha, especialistas operacionais e assessores" (MINTZBERG, 2003).

\subsection{COMPONENTES DA ESTRUTURA ORGANIZACIONAL}

O modelo de estrutura proposto por Mintzberg tornou-se popular e possibilitou estudos das questões ligadas às estruturas organizacionais e suas ligações com os contextos de atuação (URBANAVICIUS JÚNIOR, 2008).

Mintzberg considera que a inserção da palavra design nos estudos das estruturas organizacionais, significa considerar aqueles elementos que vão "girar os botões que influenciam a divisão do trabalho e os mecanismos de coordenação, que afetam as funções da organização" (MINTZBERG, 2003). O autor determina quatro designs para o entendimento desses elementos que fornecem energia à organização: design das posições, design da superestrutura, design de vínculos laterais e, design do sistema de tomada de decisão. Cada um desses denominados designs, possui um conjunto de parâmetros de design, que atuam como ferramentas que possibilitam as ações (MINTZBERG, 2003).

O Quadro 2 apresenta os referidos designs e seus respectivos parâmetros de design, bem como as definições apresentadas pelo autor para cada um deles.

Quadro 2 - Agrupamento dos parâmetros de acordo com os designs

\begin{tabular}{|l|l|}
\hline \multicolumn{1}{|c|}{ DESIGN } & \multicolumn{1}{c|}{ PARÂMETROS DE DESIGN } \\
\hline - Design das Posições & $\begin{array}{l}\text { Especialização da Tarefa: conhecimentos especializados para } \\
\text { realização das tarefas. }\end{array}$ \\
$\begin{array}{l}\text { (Situações que envolvem as posições } \\
\text { profissionais ocupadas pelos integrantes da }\end{array}$ & $\begin{array}{l}\text { Formalização do Comportamento: maneira como a organização } \\
\text { formaliza e separa seus membros, bem como a padronização dos } \\
\text { processos. }\end{array}$ \\
& $\begin{array}{l}\text { Treinamento e Doutrinação: ensino de habilidades e conhecimentos } \\
\text { relacionados ao trabalho. }\end{array}$ \\
\hline
\end{tabular}




\begin{tabular}{|c|c|}
\hline $\begin{array}{l}\text { - Design da Superestrutura } \\
\text { (Condições relativas às ações de comando } \\
\text { na organização) }\end{array}$ & $\begin{array}{l}\text { - Agrupamento em Unidades: agrupamento das posições em } \\
\text { unidades e estas em outras unidades, de maneira que estejam } \\
\text { vinculadas ao vértice estratégico. } \\
\text { - Tamanho da Unidade: dimensão de cada unidade ou grupo de } \\
\text { trabalho. }\end{array}$ \\
\hline $\begin{array}{l}\text { - Design de Vínculos Laterais } \\
\text { (Condições que envolvem a interligação } \\
\text { entre os componentes da organização) }\end{array}$ & $\begin{array}{l}\text { - Sistemas de Planejamento e Controle: instrumentos pelos quais são } \\
\text { elaborados planos para estabelecer e controlar os outputs. } \\
\text { - Instrumentos de Vínculos: instrumentos desenvolvidos para encorajar } \\
\text { os contatos entre os indivíduos, referentemente às suas ligações } \\
\text { funcionais. }\end{array}$ \\
\hline $\begin{array}{l}\text { - Design do Sistema de } \\
\text { Tomada de Decisão } \\
\text { (Condições que focalizam aç̃̃es que } \\
\text { evolvem os procedimentos profissionais) }\end{array}$ & $\begin{array}{l}\text { - Descentralização Vertical: dispersão do poder entre muitas pessoas } \\
\text { no encadeamento abaixo da autoridade de linha. } \\
\text { - Descentralização Horizontal: extensão em que os não-gerentes } \\
\text { controlam os processos de decisão. O poder pode fluir para pessoas } \\
\text { fora da linha de atuação, como analistas, especialistas, pessoal de } \\
\text { apoio e operadores. }\end{array}$ \\
\hline
\end{tabular}

Fonte: Elaborado pelos autores a partir de Mintzberg, 1980; Mintzberg, 2003.

Os parâmetros de design sofrem ação de fatores contingenciais, de maneira que uma estrutura adequada à empresa deve refletir a situação por ela vivida (MINTZBERG, 1980). O autor menciona que "a estruturação eficaz requer uma consistência entre os parâmetros de design e os fatores de contingência" (MINTZBERG, 1979). Tais fatores contingenciais, também denominados pelo autor de situacionais são alocados em quatro grupos:

- Idade e tamanho: A estrutura de uma organização reflete sua idade, ou seja, há relação entre a idade e tamanho da organização com o grau de formalização adotado (MINTZBERG, 1980).

- Sistema técnico: Quanto mais regulado e controlado for o sistema operacional, maior será o grau de formalização, assim como quanto maior for a sofisticação tecnológica aplicada, mais elaborada será a estrutura organizacional (MINTZBERG, 1980).

- Ambiente: O ambiente afeta a estrutura organizacional, de maneira a requisitar a descentralização e diferenciação nos trabalhos (MINTZBERG, 1980).
- Poder: As condições de poder determinadas às pessoas geram maior ou menor centralização, assim como distribuição das decisões (MINTZBERG, 1980).

\section{METODOLOGIA}

O estudo de natureza exploratória fundamentouse em estudo de casos múltiplos realizado com base em análise documental e entrevistas semiestruturadas com dirigentes de três empresas de grande porte. O estudo de casos múltiplos oferece possibilidade de maiores benefícios como a replicação das constatações (YIN, 2010). As entrevistas fundamentaram-se em questões abertas para que se obtivesse maior riqueza de detalhes e também questões fechadas de forma a se obter escores para as percepções dos entrevistados em escala pré-definida. Para tanto, utilizou-se escala tipo Likert (Likert, 1932) de 1 a 5 pontos com a seguinte graduação: 1(muito baixa), 2(baixa), 3(média), 4(alta) e, 5(muito alta).

As questões abertas foram analisadas a partir da técnica da análise de conteúdo com 
suporte do software Atlas T.I., de maneira a que se pudesse, a partir de codificações e criação de família de assuntos, avaliar mais objetivamente a opinião dos entrevistados. Segundo Gil (2010) esse procedimento de codificação permite que os dados sejam comparados, obtendo-se, assim, a significância dos mesmos.

A coleta de dados foi realizada com o uso de gravação autorizada, sendo posteriormente transcrita pelos autores e submetida à análise de conteúdo, buscando-se aspectos convergentes nas respostas dos sujeitos de pesquisa e também a análise com suporte do software Atlas T.I. Também se procedeu a tabulação das respostas quantitativas.

\section{CARACTERIZAÇÃO DAS EMPRESAS E APRESENTAÇÃO DOS RESULTADOS}

\subsection{EMPRESA A}

A empresa denominada A foi fundada em 1969 em um município da região da Grande São Paulo, Brasil, para atuar no transporte de veículos.

Durante trinta e cinco anos a empresa se manteve no segmento de atuação inicial, tendo como clientes grandes montadoras de automóveis. A partir de 2007, a organização adquiriu outras empresas, inclusive de outros segmentos, sendo que com o processo de abertura de capital, IPO (Initial Public Offering) sua atuação passou a ser também em outros países.
Os negócios, então, incorporaram outras atividades, além daquela originária. Nesse sentido, as novas atividades incorporadas passaram a ser acentuadamente diversificadas, a saber: serviços logísticos e aduaneiros para a exportação e importação, inspeção de qualidade e instalação de acessórios, serviços de despachante e estocagem, leilões de automóveis, transportes especializados em outras áreas diferentes daquela originária (frigoríficos, suco, produtos de alta tecnologia, cargas expressas), distribuição de encomendas adquiridas pela WEB, gestão de estoques, serviços milk-run e just-in-time, recebimento de numerários decorrentes das entregas de produtos, monitoramento de estoques, etiquetagem, selagem, lavagem de containers, consolidação de cargas e gestão de portos.

Com a abertura de capital e a entrada em novos negócios, a empresa passou a oferecer um amplo portfólio de serviços, o que demandou alterações substanciais em suas operações. Nesse sentido, a empresa passou a considerar novos valores em seus negócios, oriundos de igualmente novo modelo de negócio, com aproveitamento de recursos e demanda de novos.

No âmbito dos recursos humanos, a empresa conta com efetivo de mais de 1600 pessoas, incluindo-se nesse total os funcionários diretos e profissionais atuantes como transportadores terceirizados.

A Figura 1 ilustra o momento da ruptura da empresa com o modelo de negócio anterior e o instante da mudança significativa no mesmo. 
Figura 1 - Linha do tempo da empresa A com identificação do momento de ocorrência da alteração significativa no modelo de negócio.

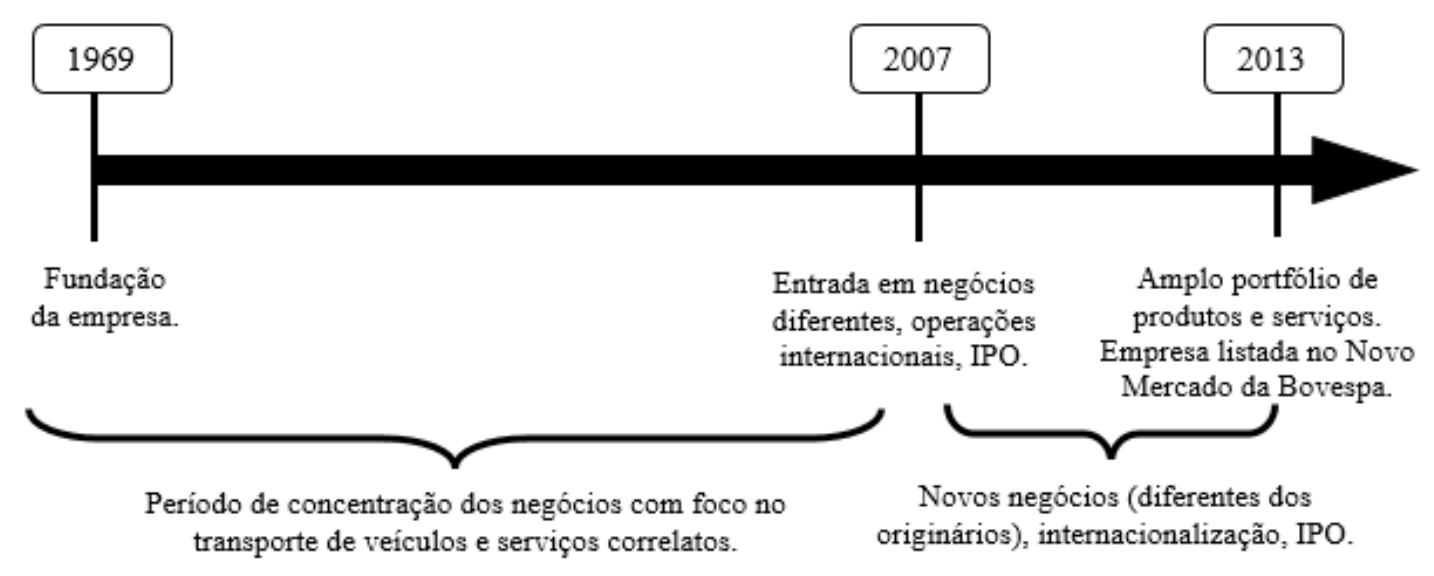

Fonte: elaborado pelos autores a partir das entrevistas realizadas e dos dados coletados.

A pesquisa possibilitou constatar a mudança no modelo de negócio com base nas seguintes características:
a) Satisfação de necessidades de mercado até então não atendidas:

Esse ponto foi relevante para se detectar mudança significativa no modelo de negócio, uma vez que a empresa adquiriu outras com focos em negócios que não estavam sendo atendidos até então. Nesse contexto a abertura de filial em outro país, trouxe à empresa a necessidade de se aprimorar em atividades e se estruturar para atender aquela nova demanda.

b) Entrega de novos produtos, serviços ou tecnologia ao mercado:

Nesse aspecto a empresa passou a entregar ao mercado novos serviços até então realizados apenas por empresas de outras características que não a de uma empresa de logística. É o caso da empresa de leilões automotivos e entrega de bens adquiridos pelo comércio eletrônico, sendo esse último serviço prestado com ampla gama de tecnologia. Para a empresa pesquisada foram alterações importantes em sua relação de valor com o mercado, uma vez que não havia em seu portfólio tais produtos, serviços e o emprego da tecnologia.

c) Aprimoramento ou transformação de um mercado já existente:

Ao passar a ofertar novos negócios e serviços ao seu mercado de atuação, a empresa passou a se destacar, provocando melhorias nos serviços que estavam sendo até então prestados, como os serviços de transporte de produtos adquiridos no comércio eletrônico, por exemplo. A empresa adquiriu outras duas para ofertar de maneira aprimorada tais serviços, ou seja, enquanto uma das adquiridas passou a efetuar serviços de entrega de encomendas (pequenos volumes), a outra adquirida se especializou nas entregas de volumes maiores, como bens duráveis.

d) Geração de novo mercado:

A empresa praticamente criou novos mercados para suas operações em diversos segmentos. Se 
no início era apenas o segmento de transporte de veículos, com a alteração no modelo de negócios, passou a atuar em diversos e diferentes mercados, a saber: serviços aduaneiros relativos à importação e exportação, instalação de acessórios, inspeção de qualidade e revisão de veículos, serviços de documentação de veículos (despachante), transportes especializados (frigoríficos, sucos e produtos químicos), distribuição de encomendas, entregas de volumes, gestão de estoques e porto seco e, embalagens.

Observa-se na empresa $A$ que os quatro quesitos de alterações nos modelos de negócios foram atendidos, caracterizando-se mudança significativa. Por outro lado, a entrevista com o sujeito de pesquisa, representante da empresa, corrobora a constatação de mudança significativa do modelo de negócio com base em sua percepção. Considerando a escala Likert de cinco pontos, o sujeito da pesquisa classificou a intensidade da mudança no modelo de negócio como muito alta, ou seja, a pontuação máxima na escala.

\subsection{EMPRESA B}

A empresa B atua nos segmentos de comunicação e Educação. O início dos negócios se deu em 1995, quando foi fundada no estado do Rio de Janeiro uma escola que ministrava cursos livres do idioma inglês, observando-se crescimento das unidades em todo Brasil até o ano de 2003, quando atingiu a marca de quarenta unidades. A sede do grupo está localizada no estado do Paraná.

A inovação sempre foi o ponto principal dos investimentos em P\&D, tornando-se, com o passar do tempo o foco principal. "Na sequência de sua evolução, preocupou-se com sustentabilidade, o que a levou a investir em pesquisa e desenvolvimento. Surgia, assim, um novo foco para a empresa, a inovação" (ENTREVISTADO DA EMPRESA B).

Em 2003 a empresa criou um novo negócio voltado unicamente para o ensino do idioma em plataformas de extração de petróleo. Com a evolução dos investimentos em pesquisa e desenvolvimento, a empresa passou, então, a oferecer cursos para públicos específicos, como crianças, jovens e executivos.

Novas oportunidades surgiram e a empresa percebeu oportunidade de alterar seu modelo de negócio, com foco em novas operações. Assim, foi criada uma empresa de franquia especializada em franquear escolas de inglês e atender primordialmente sua própria rede. Também foram criadas três editoras, inclusive no exterior, para aquisição, estocagem e distribuição dos materiais gráficos usados por todas as empresas do grupo, não apenas as escolas de inglês.

O grupo criou também uma empresa produtora de audiovisual, responsável pela geração de materiais como filmes publicitários e longasmetragens. Além de fazer a cobertura de todos os eventos das organizações do grupo, a empresa de audiovisual também atua na atualização dos sites das mesmas, assim como atualização diária do conteúdo jornalístico utilizado pelas demais unidades. A referida unidade também presta serviços para empresas fora do grupo.

Nesse ambiente de expansão e de mudança de seu modelo de negócios, o grupo criou uma empresa que presta serviços de comunicação também para empresas fora do grupo, tanto no mercado nacional quanto no mercado internacional, atuando com 
os seguintes produtos: ações de publicidade, propaganda, merchandising e promoções.

O entrevistado mostrou ainda a dimensão atual dos negócios, ao informar que a empresa atualmente focaliza a educação, a comunicação e a geração de conteúdos, frutos do foco inicial em pesquisa e desenvolvimento: "Hoje é uma empresa de educação e comunicação e trabalha também na geração de conteúdos, fruto do foco em pesquisa e desenvolvimento" (ENTREVISTADO DA EMPRESA B).

O conglomerado empresarial conta com mais de 19000 funcionários, sendo que no ano de 2013 teve seu controle acionário assumido por outro grupo empresarial, não se descartando na ocasião os negócios.

Constatou-se que a mudança no modelo de negócio ocorreu a partir do ano 2000, quando a empresa entrou fortemente em outros segmentos, diferentes daquele em que operava inicialmente. Desde então, a empresa relata que há constante reafirmação do foco em inovação.

A Figura 2 apresenta a linha do tempo da referida empresa, e o momento da modificação significativa em seu modelo de negócio.

Figura 2 - Linha do tempo da empresa B com identificação do momento da alteração significativa no modelo de negócio.

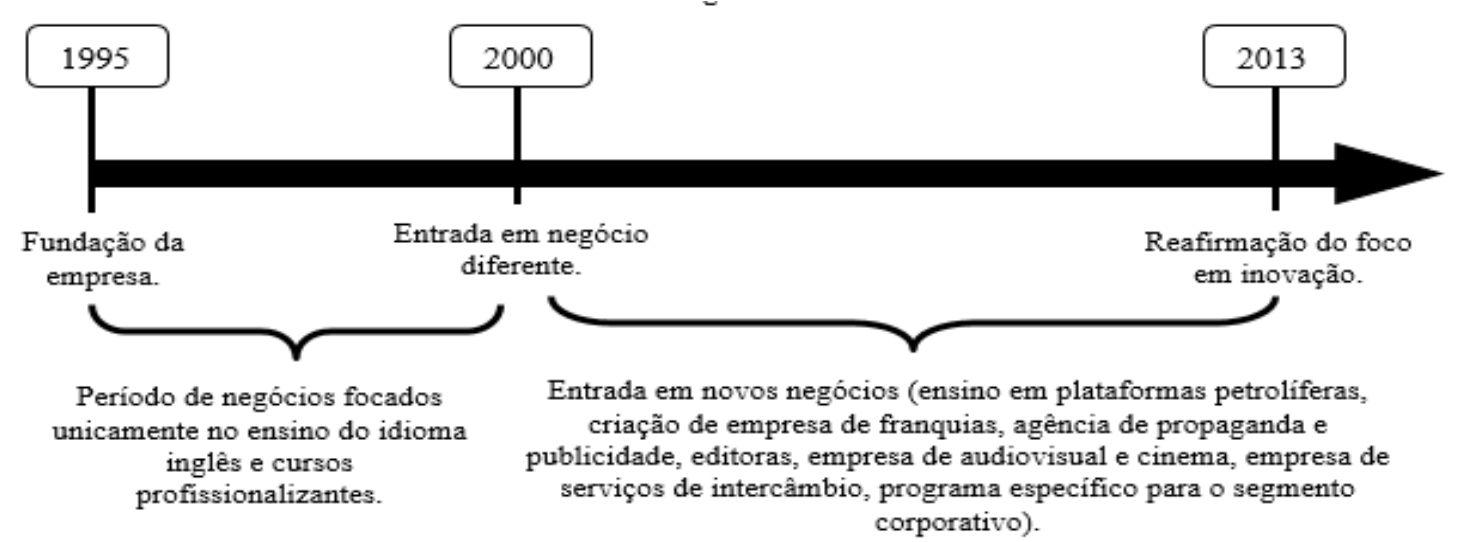

Fonte: elaborado pelos autores a partir das entrevistas realizadas e dos dados coletados.

A pesquisa possibilitou constatar a mudança no modelo de negócio com base nas seguintes características:

a) Satisfação de necessidades de mercado até então não atendidas:

Ao optar pelo negócio de ensino de idioma em plataformas petrolíferas em alto mar, a empresa desenvolveu tecnologia de ensino que possibilitou atender a necessidade de aprender o idioma no local de trabalho, mesmo com o confinamento que aquela atuação profissional determina. São várias semanas longe do ambiente natural de trabalho, o que implica em que o a operação de ensino do idioma ocorra na própria plataforma, atendendo assim, a necessidade de aprendizado que até então não podia ser suprida. Assim, observa-se que a empresa atendeu plenamente ao quesito de satisfação de necessidade até então não atendida.

Já no ano 2000 a empresa criou um negócio de franquias, que além de dar suporte às operações desenvolvidas, também iniciou negócio diferente para a rede. 
b) Entrega de novos produtos, serviços ou tecnologia ao mercado:

Com a introdução do ensino de idioma em plataformas petrolíferas, a empresa passou a empregar recursos diferenciados para atender a tal necessidade, incluindo tecnologia diferenciada. Tratou-se de uma operação até então não incluída no portfólio da empresa, o que exigiu adaptações e ajustes em suas condições de atuação no mercado.

Outros negócios também passaram a fazer parte da empresa, como empresa de franquias, agência de propaganda e publicidade, editoras, empresa de audiovisual, empresa de intercâmbio internacional.

Isso posto, percebe-se que os novos produtos e serviços entregues ao mercado, além de darem suporte às atividades do próprio grupo, também passaram a fazer parte de seu portfólio ofertado ao mercado. Trata-se de produtos, serviços e tecnologia que até então estavam fora do domínio da empresa, que os passou a entregar ao mercado a partir de suas concepções. Dessa forma, a empresa se enquadrou no quesito de entregar novos produtos, serviços ou tecnologia ao mercado.

c) Aprimoramento ou transformação de um mercado já existente:

Em sua escalada de inovações, a empresa também aprimorou os negócios até então existentes. Nesse sentido, observou-se que foram criados cursos diferenciados de idiomas, como por exemplo: criação de empresa especializada em cursos de idiomas no ambiente corporativo, criação de empresa com curso de idioma com todas as idades juntas e, criação de empresa com curso de inglês unicamente para adolescentes.

Esse aprimoramento no mercado, até então já operado pela empresa, confirma sua intenção em inovar de maneira constante, além de possibilitar o enquadramento da empresa na condição proposta pelo terceiro quesito: Aprimoramento ou transformação de um mercado já existente.

d) Geração de novo mercado:

O conjunto de novos negócios, nos quais a empresa passou a operar, demonstram sua iniciativa de inovação. Com negócios em diversos segmentos até então não operados, a empresa desenvolveu novos mercados que contribuíram de maneira importante para seu desenvolvimento nos últimos anos.

Pode-se constatar que além do negócio de idiomas e ensino profissionalizante, a empresa passou a operar também nos seguintes segmentos: franquia, publicidade e propaganda, editorial, produção audiovisual e cinematográfica e, intercâmbio internacional.

Isso posto, pode-se confirmar que a empresa atendeu o quesito de geração de novo mercado para sua atuação.

Uma vez constatado o atendimento pela empresa dos quatro quesitos considerados, conclui-se pelos critérios adotados que ocorreu, de fato, mudança significativa no modelo de negócio da empresa $B$. Tal condição foi corroborada na entrevista realizada com o sujeito de pesquisa da referida empresa, que demonstrou sua percepção de que a alteração do modelo de negócio atingiu cinco pontos na escala Likert de um a cinco, ou seja, a pontuação máxima.

\subsection{EMPRESA C}

A empresa C foi fundada em 1920 nos EUA para fabricar balões de brinquedos, a partir da borracha, desenvolvendo seu portfólio de produtos 
naquele segmento. Na década de 1950 a empresa diversificou os produtos passando a fabricar tapetes para o segmento hoteleiro, o que possibilitou o desenvolvimento de tecnologias apropriadas no trato com borracha. A partir dos anos sessenta, a empresa se consolidou como atuante na fabricação de produtos oriundos de borracha, desenvolvendo artefatos apropriados a diversos outros segmentos, como agrícola e industrial. No ano de 1999, a empresa se fundiu com uma empresa americana especializada em fabricação e varejo de produtos de massa. Surgia assim, uma empresa de porte muito maior, mas com um novo modelo de atuação, com novos produtos e atendendo novos segmentos. Na sequência dos fatos, passou à aquisição de organizações em diversos segmentos até então não operantes em seu portfólio, como produtos médicos, sinalizadores, ferramentas e materiais de construção, higiene, carros de bebês, material de escrita e escritório, serras, dentre outros.

Em âmbito global a empresa mantém em seus quadros um contingente de aproximadamente 20.000 pessoas, com faturamento anual da ordem de US\$ 8 bilhões. Em relação às unidades produtivas, a organização possui quatro plantas de fabricação nos EUA, uma no Brasil e uma no México, além de rede de representantes em diversos países. A sede da empresa encontra-se na cidade de Atlanta, Estado da Georgia, EUA, com escritório de Administração no Brasil, localizado na cidade de São Paulo.

Em seu portfólio apresenta atualmente em torno de 70 produtos agrupados em unidades de negócios em seis segmentos, a saber: Bebês, Produtos Comerciais, Materiais de Escritório, Ferramentas, Lar e, Especialidades.

A empresa se manteve no mesmo negócio por praticamente oitenta anos, sendo que em 1999, após fusão com outra grande empresa do segmento de varejo de produtos de massa, passou por alteração em seu portfólio de atuação. Assim, de origem tipicamente fabril no segmento de borracha, a empresa passou a operar em segmentos até então novos. O momento da alteração significativa do modelo de negócio encontra-se apresentado na Figura 3.

Figura 3 - Linha do tempo da empresa C com identificação do momento de ocorrência da alteração significativa no modelo de negócio.

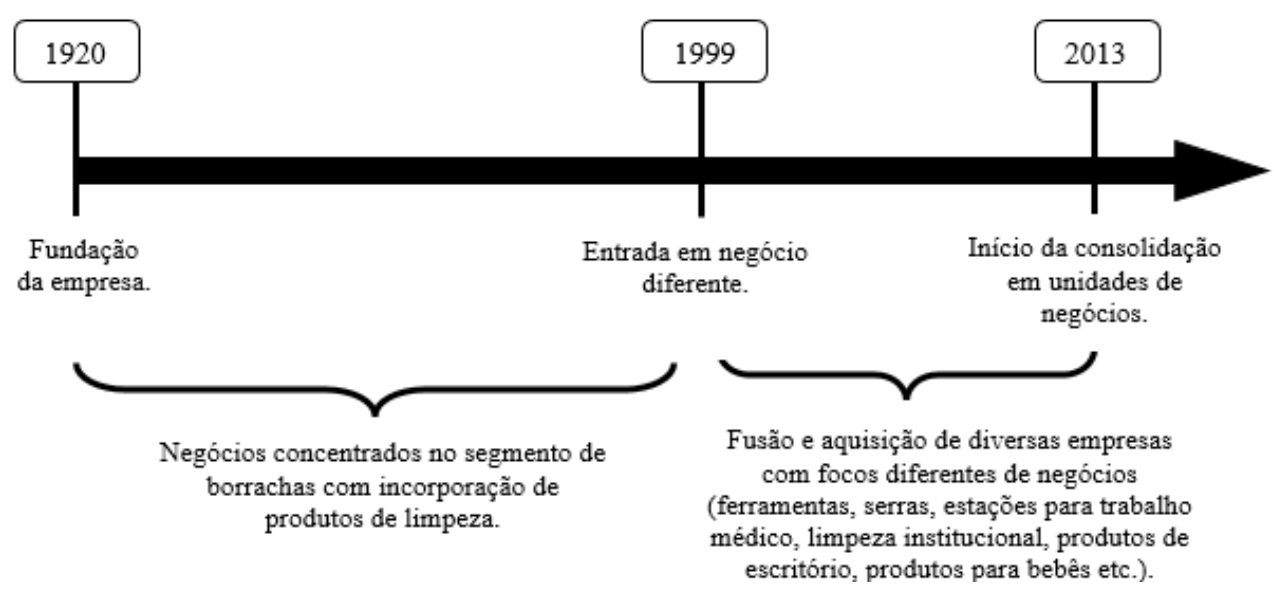

Fonte: elaborado pelos autores a partir das entrevistas realizadas e dos dados coletados 
A pesquisa possibilitou constatar a mudança no modelo de negócio com base nas seguintes características:

a) Satisfação de necessidades de mercado até então não atendidas:

Com a entrada em diversos segmentos diferentes daqueles até então operados pela empresa, esta passou a atender a necessidades não atendidas até então, como por exemplo, estações de trabalho para a área médica, apropriadas para serviços de telemedicina. Para a empresa trata-se de um mercado inexplorado até então e que passou a fazer parte de seu portfólio de produtos exigindo novas operações.

Mesmo em seu portfólio originário, a empresa também passou a atender a necessidades de mercado que não eram atendidas, como por exemplo, baldes-espremedores e conchas plásticas para uso doméstico.

Dessa maneira, pode-se observar que o quesito foi atendido pela empresa.

b) Entrega de novos produtos, serviços ou tecnologia ao mercado:

Novos produtos e novas tecnologias foram desenvolvidos pela empresa e entregues aos mercados. Podem ser citados como exemplos, a aquisição de empresa especializada em ferramentas de corte, ou seja, serras, e também o desenvolvimento de tecnologia de limpeza institucional. Nesse último caso, a empresa optou pela aquisição de outra organização que atuava no segmento, incorporando novas tecnologias em seu segmento.

Além desses exemplos pode-se observar que com as diversas aquisições de empresas e criação de divisão especializada, a empresa passou a entregar produtos, serviços e tecnologias que até então não entregava ao mercado de atuação.

Essas condições demonstram que o quesito de entrega de novos produtos, serviços e tecnologias ao mercado foi atendido pela empresa.

c) Aprimoramento ou transformação de um mercado já existente:

A entrada da empresa no segmento de limpeza institucional pode ser considerada como um aprimoramento em segmento já existente; porém, novo para ela. Para esse segmento a empresa desenvolveu produtos específicos, como carros de limpeza e baldes-espremedores, o que exigiu alterações em seu conjunto de operações e tecnologias.

Além disso, é possível verificar também que as estações de telemedicina representaram um forte aprimoramento nos produtos até então existentes, uma vez que passaram a ser confeccionados com materiais especiais, desenvolvidos pela empresa.

Isso posto, pode-se verificar que a empresa atende a esse quesito de aprimoramento ou transformação de um mercado já existente.

d) Geração de novo mercado:

Todas as movimentações empresariais verificadas com a empresa $\mathrm{C}$ significaram novos produtos e novos serviços, o que identicamente significaram novos mercados de atuação para a empresa. Considerando que sua marca inicial era a fabricação de produtos de borracha, a empresa atualmente atua em segmentos diferentes daquele, além dele.

Essa condição faz com que a empresa atenda ao quesito de geração de novo mercado em sua atuação. 
Assim, ao atender as quatro condições estabelecidas para alteração significativa do modelo de negócio, confirma-se a referida situação. O interlocutor da organização entende que a intensidade da mudança no modelo de negócio é muito alta. Tal condição pode ser confirmada quando observada a assinalação do entrevistado na escala Likert de um a cinco pontos, na qual a assinalação pelo sujeito da pesquisa foi de cinco pontos, ou seja, a máxima.

\subsection{AVALIAÇÃO DA MUDANÇA NA ESTRUTURA ORGANIZACIONAL (EMPRESAS A, B E C)}

Constatou-se que as três empresas pesquisadas alteraram significativamente seus modelos de negócios, uma vez que os quatros pontos considerados para tal caracterização foram constatados.

Apurou-se também que as estruturas também foram alteradas em todos os componentes considerados por Mintzberg. Nesse sentido a pesquisa identificou:

a) Todos os parâmetros de design e fatores situacionais de Mintzberg foram considerados de muito alta importância e modificados em elevada intensidade, para implantação dos novos modelos de negócios.

A tabela 1 apresenta os resultados a partir da pontuação gerada na escala tipo Likert, de 1 a 5, obtidas a partir das respostas obtidas na pesquisa.

Tabela 1 - Estrutura organizacional: importância e intensidade dos Parâmetros de Design e Fatores Situacionais.

\begin{tabular}{|c|c|c|c|c|c|}
\hline \multirow{2}{*}{ Empresas } & \multirow{2}{*}{$\begin{array}{l}\text { Parâmetros de Design e Fatores } \\
\text { Situacionais ou Contingenciais }\end{array}$} & \multicolumn{2}{|c|}{ Importância } & \multicolumn{2}{|c|}{ Intensidade da Mudança } \\
\hline & & Classificação & Pont. & Classificação & Pont. \\
\hline \multirow{14}{*}{ Empresa A } & Média & Alta & 4,3 & Média & 3,9 \\
\hline & Formalização do Comportamento & Muito Alta & 5 & Muito Alta & 5 \\
\hline & Ambiente & Muito Alta & 5 & Muito Alta & 5 \\
\hline & Especialização da Tarefa & Muito Alta & 5 & Alta & 4 \\
\hline & Sistemas de Planej. e Controle & Muito Alta & 5 & Alta & 4 \\
\hline & Treinamento e Doutrinação & Muito Alta & 5 & Média & 3 \\
\hline & Agrupamento em Unidades & Alta & 4 & Alta & 4 \\
\hline & Tamanho da Unidade & Alta & 4 & Alta & 4 \\
\hline & Descentralização Horizontal & Alta & 4 & Alta & 4 \\
\hline & Descentralização Vertical & Alta & 4 & Alta & 4 \\
\hline & Poder & Alta & 4 & Alta & 4 \\
\hline & Sistema Técnico & Alta & 4 & Alta & 4 \\
\hline & Instrumentos de Vínculos & Alta & 4 & Média & 3 \\
\hline & Idade e Tamanho & Média & 3 & Média & 3 \\
\hline
\end{tabular}




\begin{tabular}{|c|c|c|c|c|c|}
\hline \multirow{2}{*}{ Empresas } & \multirow{2}{*}{$\begin{array}{l}\text { Parâmetros de Design e Fatores } \\
\text { Situacionais ou Contingenciais }\end{array}$} & \multicolumn{2}{|c|}{ Importância } & \multicolumn{2}{|c|}{ Intensidade da Mudança } \\
\hline & & Classificação & Pont. & Classificação & Pont. \\
\hline \multirow{14}{*}{ Empresa B } & Média & Muito Alta & 5,0 & Muito Alta & 5,0 \\
\hline & Agrupamento em Unidades & Muito Alta & 5 & Muito Alta & 5 \\
\hline & Ambiente & Muito Alta & 5 & Muito Alta & 5 \\
\hline & Descentralização Horizontal & Muito Alta & 5 & Muito Alta & 5 \\
\hline & Descentralização Vertical & Muito Alta & 5 & Muito Alta & 5 \\
\hline & Especialização da Tarefa & Muito Alta & 5 & Muito Alta & 5 \\
\hline & Formalização do Comportamento & Muito Alta & 5 & Muito Alta & 5 \\
\hline & Idade e Tamanho & Muito Alta & 5 & Muito Alta & 5 \\
\hline & Instrumentos de Vínculos & Muito Alta & 5 & Muito Alta & 5 \\
\hline & Poder & Muito Alta & 5 & Muito Alta & 5 \\
\hline & Sistema Técnico & Muito Alta & 5 & Muito Alta & 5 \\
\hline & Sistemas de Planej. e Controle & Muito Alta & 5 & Muito Alta & 5 \\
\hline & Tamanho da Unidade & Muito Alta & 5 & Muito Alta & 5 \\
\hline & Treinamento e Doutrinação & Muito Alta & 5 & Muito Alta & 5 \\
\hline \multirow{14}{*}{ Empresa C } & Média & Alta & 4,4 & Alta & 4,4 \\
\hline & Agrupamento em Unidades & Muito Alta & 5 & Muito Alta & 5 \\
\hline & Especialização da Tarefa & Muito Alta & 5 & Muito Alta & 5 \\
\hline & Idade e Tamanho & Muito Alta & 5 & Muito Alta & 5 \\
\hline & Treinamento e Doutrinação & Muito Alta & 5 & Muito Alta & 5 \\
\hline & Tamanho da Unidade & Alta & 4 & Muito Alta & 5 \\
\hline & Ambiente & Alta & 4 & Alta & 4 \\
\hline & Descentralização Horizontal & Alta & 4 & Alta & 4 \\
\hline & Descentralização Vertical & Alta & 4 & Alta & 4 \\
\hline & Formalização do Comportamento & Alta & 4 & Alta & 4 \\
\hline & Instrumentos de Vínculos & Alta & 4 & Alta & 4 \\
\hline & Poder & Alta & 4 & Alta & 4 \\
\hline & Sistema Técnico & Alta & 4 & Alta & 4 \\
\hline & Sistemas de Planej. e Controle & Alta & 4 & Alta & 4 \\
\hline \multirow{14}{*}{$\begin{array}{c}\text { Média } \\
(\mathrm{A}, \mathrm{B} \text { e } \mathrm{C})\end{array}$} & Média & Muito Alta & 4,6 & Alta & 4,4 \\
\hline & Especialização da Tarefa & Muito Alta & 5,0 & Muito Alta & 4,7 \\
\hline & Agrupamento em Unidades & Muito Alta & 4,7 & Muito Alta & 4,7 \\
\hline & Ambiente & Muito Alta & 4,7 & Muito Alta & 4,7 \\
\hline & Formalização do Comportamento & Muito Alta & 4,7 & Muito Alta & 4,7 \\
\hline & Tamanho da Unidade & Muito Alta & 4,7 & Muito Alta & 4,7 \\
\hline & Treinamento e Doutrinação & Muito Alta & 5,0 & Alta & 4,3 \\
\hline & Sistemas de Planej. e Controle & Muito Alta & 4,7 & Alta & 4,3 \\
\hline & Descentralização Horizontal & Alta & 4,3 & Alta & 4,3 \\
\hline & Idade e Tamanho & Alta & 4,3 & Alta & 4,3 \\
\hline & Instrumentos de Vínculos & Alta & 4,3 & Alta & 4,3 \\
\hline & Poder & Alta & 4,3 & Alta & 4,3 \\
\hline & Sistema Técnico & Alta & 4,3 & Alta & 4,3 \\
\hline & Descentralização Vertical & Alta & 4,3 & Alta & 4,0 \\
\hline
\end{tabular}

Fonte: elaborado pelos autores a partir das entrevistas realizadas. 
As questões pontuadas pelos sujeitos de pesquisa na escala tipo Likert de 1 a 5, indicaram que no conjunto das três empresas a média para questões referentes à Configuração de Valor, em que se encontra a estrutura organizacional, recebeu pontuação média de 4,7, ou seja, muito alta. A referida pontuação foi atribuída à importância que os respondentes atribuíram para tal quesito. Já em relação à intensidade com que alteraram as estruturas, a pontuação foi a máxima, ou seja, 5,0 , refletindo e corroborando suas declarações de que a intensidade da mudança na estrutura organizacional foi muito elevada.

Essas condições confirmam a importância das questões da estrutura organizacional no ambiente de negócios significativamente alterados nas empresas pesquisadas.

b) As menções acerca da infraestrutura, na qual está inserida a estrutura organizacional, foram aquelas que maior frequência relativa tiveram no total de menções constatadas nas entrevistas realizadas. Por outro lado, o item específico denominado de configuração de valor, que se refere à estrutura organizacional, é o terceiro mais citado pelos sujeitos de pesquisas. Na análise de conteúdo com suporte de software, as questões referentes à Configuração de Valor, foram as mais detectadas nas entrevistas com os sujeitos de pesquisa. Do total de 85 menções referentes aos componentes dos blocos constitutivos dos modelos de negócios, 13 delas, ou seja, $15,29 \%$ referiram-se à Configuração de Valor.

A tabela 2 apresenta os resultados mencionados, considerando que:

- os pilares de sustentação dos modelos de negócios foram denominados de categorias familiares para efeitos de utilização no software Atlas T.I.

- os blocos constitutivos de cada pilar de sustentação foram denominados de códigos para utilização do referido software.

- As frequências de citações são apresentadas em três categorias: i) absoluta: contém o total de citações referentes a cada bloco constitutivo; ii) relativa à categoria familiar: apresenta a participação relativa de cada código no total da categoria familiar específica; iii) relativa ao total das categorias familiares: apresenta a participação relativa de cada código no conjunto de todas as categorias familiares.

Tabela 2 - Modelo de Negócio: frequência de citação dos pilares e blocos constitutivos

\begin{tabular}{|c|c|c|c|c|}
\hline $\begin{array}{l}\text { Categoria familiar } \\
\text { (Pilar de Sustentação) }\end{array}$ & $\begin{array}{l}\text { Código } \\
\text { (Bloco Constitutivo) }\end{array}$ & $\begin{array}{l}\text { Frequência absoluta } \\
\text { de ocorrências } \\
\text { (citações) }\end{array}$ & $\begin{array}{l}\text { Frequência relativa à } \\
\text { categoria familiar }\end{array}$ & $\begin{array}{l}\text { Frequência relativa } \\
\text { ao total das } \\
\text { categorias familiares }\end{array}$ \\
\hline \multirow{4}{*}{$\begin{array}{l}\text { Gestão de } \\
\text { Infraestrutura }\end{array}$} & Configuração de Valor & 13 & $44,83 \%$ & $15,29 \%$ \\
\hline & Relacionamento com Parceiros & 11 & $37,93 \%$ & $12,94 \%$ \\
\hline & Competências Essenciais & 05 & $17,24 \%$ & $05,88 \%$ \\
\hline & & 29 & $100,00 \%$ & $34,12 \%$ \\
\hline
\end{tabular}




\begin{tabular}{|c|c|c|c|c|}
\hline \multirow{4}{*}{$\begin{array}{l}\text { Relacionamento com } \\
\text { Clientes }\end{array}$} & Cliente-Alvo & 15 & $51,72 \%$ & $17,65 \%$ \\
\hline & Canal de Distribuição & 09 & $31,04 \%$ & $10,59 \%$ \\
\hline & Relacionamento & 05 & $17,24 \%$ & $05,88 \%$ \\
\hline & & 29 & $100,00 \%$ & $34,12 \%$ \\
\hline \multirow[t]{2}{*}{ Produto } & Proposta de Valor & 16 & $100,00 \%$ & $18,82 \%$ \\
\hline & & 16 & $100,00 \%$ & $18,82 \%$ \\
\hline \multirow{3}{*}{$\begin{array}{l}\text { Aspectos } \\
\text { Financeiros }\end{array}$} & Estrutura de Custos & 06 & $54,55 \%$ & $07,06 \%$ \\
\hline & Fluxo de Receita & 05 & $45,45 \%$ & $05,88 \%$ \\
\hline & & 11 & $100,00 \%$ & $12,94 \%$ \\
\hline \multicolumn{2}{|l|}{ Total de menções } & 85 & & \\
\hline
\end{tabular}

Fonte: Elaborada pelos autores a partir da análise de conteúdo com suporte de software.

c) As três empresas pesquisadas adotaram a estrutura divisionada, ou seja, para efetivar os novos modelos de negócios foram implantadas unidades de negócios com áreas de serviços compartilhados dando suporte a elas. Os relatos dos entrevistados evidenciam tal situação:

“Era uma só unidade de negócio, fundamentalmente uma empresa com uma estrutura única e depois do IPO nós criamos as unidades de negócios" (ENTREVISTADO DA EMPRESA A).

“...houve o desdobramento e outras empresas foram criadas... foram criadas estruturas regionais, nacionais e internacionais" (ENTREVISTADO DA EMPRESA B).

"... agrupando mais o portfólio... agrupando marcas e produtos em segmentos... agora é tudo a mesma coisa, estão todos abaixo de um mesmo guarda-chuva... hoje tem seis segmentos que agrupam as diferentes marcas... é como se fosse um gestor para cada unidade de negócio" (ENTREVISTADO DAEMPRESA C).

Os sujeitos de pesquisa relataram que os resultados foram muito favoráveis e que caso as alterações na estrutura não tivessem sido empregadas, os resultados não seriam os mesmos, com consequências indesejáveis para suas empresas.

d) As três empresas pesquisadas promoveram alterações em suas estruturas organizacionais simultaneamente às modificações significativas nos modelos de negócios. Tal ação foi relatada pelos sujeitos de pesquisa para possibilitar o devido alinhamento entre ambos e permitir que os resultados estivessem sustentados.

e) Nas três empresas analisadas a estrutura organizacional passou a ser do tipo Divisionada, com apoio de áreas centrais para o suprimento de serviços compartilhados. 
f) O envolvimento das pessoas nas questões da nova estrutura organizacional apresentou resultado favorável, constatando-se, inclusive, relato de que essa condição possibilitou a adoção de novos negócios no âmbito internacional.

O novo modelo de negócio possibilitou a delegação de poder e essa trouxe como resultado "crescimento, sentimento de pertinência" (ENTREVISTADO DA EMPRESA B).

O novo modelo de negócio possibilitou a delegação de poder e essa trouxe como resultado a possibilidade de "criar produtos específicos para o país [...] eles (funcionários) estão próximos à necessidade do consumidor local" (ENTREVISTADO DA EMPRESA C).

\section{CONSIDERAÇÕES FINAIS}

Muitas pesquisas se dedicam à análise dos componentes do modelo de negócio relacionados a o que fazer - posicionamento e escopo do produto - e para quem fazer - segmento de clientes - e esta pesquisa concentrou-se em um componente pouco visível e estudado, mas de fundamental importância para a operação do modelo de negócio, que é a estrutura organizacional.

A estrutura organizacional adotada por uma empresa deveestaralinhadaaosoutroscomponentes de seu modelo de negócio, sendo um dos pilares do modelo operacional e da configuração de valor. A metodologia desenvolvida possibilitou identificar três empresas que tiveram uma significativa mudança em seus modelos de negócios e a descrição do momento de ruptura, bem como das mudanças essenciais. Adicionalmente, identificouse que as três empresas analisadas alteraram de maneira importante os denominados parâmetros de design e fatores contingenciais ou situacionais relacionados à estrutura organizacional, visando o alinhamento com os novos modelos de negócios.

Pelos dados coletados junto às empresas pesquisadas, observou-se que a adoção da estrutura Divisionada também requisitou a incorporação de área de serviços compartilhados, de maneira que se obtivessem custos fixos menores e houvesse efeito sinérgico nos serviços prestados às unidades de negócios.

Constatou-se, por meio das entrevistas analisadas com base em análise de conteúdo, que as alterações nas estruturas organizacionais foram efetivadas simultaneamente às modificações nos modelos de negócios de maneira que fosse possível o adequado alinhamento entre ambos.

De acordo com os entrevistados, o envolvimento das pessoas nas modificações da estrutura organizacional apresentou resultados favoráveis, podendo se destacar como efeito da delegação, a proximidade com clientes e o consequente desenvolvimento de produtos específicos para tais públicos.

Os resultados obtidos refletem a importância da necessidade de constante alinhamento da estrutura organizacional ao modelo de negócio, sendo que estudos futuros podem ser desenvolvidos para que se aprofunde em cada um dos parâmetros de design e fatores situacionais ou contingenciais propostos por Mintzberg. 


\section{REFERÊNCIAS}

AMIT, Raphael; ZOTT, Christoph. Creating value through business model innovation. Mit Sloan Management Review, Massachusetts, p. 4149. Spring 2012.

BARDIN, Laurence. Análise de conteúdo. São Paulo: Edições 70, 2011, 279p.

BIASCA, Rodolfo E. Resizing reestruturando, replanejando e recriando a empresa para conseguir competitividade. Rio de Janeiro: Campus, 1995.

BURTON, Richard M.; DESANCTIS, Gerardine, OBEL, Borge. Organizational design: stepby-step approach. Cambridge: Cambridge, 2010. 235p.

CARREIRA, Dorival. Organização, sistemas e métodos. São Paulo: Saraiva, 2009. 366p.

CHESBROUGH, Henry. Modelos de negócios abertos. Porto Alegre: Bookman, 2012. 220p.

CURY, Antonio. Organização e métodos: uma visão holística. 7. ed. São Paulo: Atlas, 2000. 589p.

ETZIONI, Amitai. The active society: a theory of societal and political process. New York: The Free Prees, 1968. 698p.

FAYOL, Henri. Administração industrial e geral. 9. ed. São Paulo: Atlas, 1978. 138p.

FILARDI, Fernando; MURAD, Eduardo. Negociação empresarial. São Paulo: Saraiva, 2014. 152p.
GIL, Antonio Carlos. Como elaborar projetos de pesquisas. 5. ed. São Paulo: Atlas, 2010. 184p.

GONÇALVES, José Ernesto Lima. As empresas são grandes coleções de processos. Revista de Administração de Empresas/FGV, São Paulo, v. 40, n. 1, p. 6-19, jan./mar. 2000.

GOUVEIA, Luís Borges. Negócio electrónico conceitos e perspectivas de desenvolvimento. São João do Estoril: Sociedade Portuguesa de Inovação, 2006. 160p.

KARADIMAS, Nikolaos V.; LOUMOS, Vassili; TSIGKAS, Alexander. Sel organizing structures of ad-hoc cooperations for custom made products and services. 20th European Conference on Modelling and Simulation Wolfgang Borutzky, Alessandra Orsoni, Richard Zobel, ECMS, Proceedings [...] 2006. Disponível em: http://www.scs-europe.net/ services/ecms2006/ecms2006 \%20pdf/85-lbs.pdf. Acesso em: 23 jun. 2012.

LIKERT, Rensis. A technique for the measurement of attitudes. Archives of Psychology, New York, v.22, n.140, 5-55, jun. 1932.

LUNENBURG, Fred C. Organizational structure: Mintzberg's framework. International Journal of Scholarly, Academic, Intelectual Diversity, v. 14, n. 1, 2012. 


\section{REFERÊNCIAS}

MADEIRA, Gilberto dos Santos; PEREIRA, Moacir. Desenhando estruturas organizacionais: das burocracias de Weber e Mintzberg às organizações contemporâneas. In: CONVIBRA CONGRESSO VIRTUAL BRASILEIRO DE ADMINISTRAÇÃO, 8., p. 1-14, 2011, Anais eletrônicos [...]. Disponível em: http:// www.convibra.com.br/upload/paper/adm/ adm_2477.pdf. Acesso em: 03 jul. 2013.

MAGRETTA, Joan. A importância dos modelos de negócio. Revista Exame.com, São Paulo, julho de 2002. Disponível em: <http:// exame.abril.com.br/noticia/a-importancia-dosmodelos-de-negocio-m005 047>. Acesso em: 14 abr. 2014.

MINTZBERG, Henry. Criando organizações eficazes estruturas em cinco configurações.

2. ed. São Paulo: Atlas, 2003. 334p.

MINTZBERG, Henry. Structure in 5'S: a synthesis of the research on organization design. Management Science/University of Maryland, Baltimore, v.26, n. 3, p. 322-341, mar.1980.

MINTZBERG, Henry. The structuring of organizations: a synthesis of the research. New Jersey: Prentice Hall, 1979. 512p.

MONTANA, Patrick J.; CHARNOV, Bruce $H$. Administração. 3. ed. São Paulo: Saraiva, 2010, 525p.
MONTANA, Patrick J.; CHARNOV, Bruce $H$. Management: a streamlined course for students and business people, Barron's Review Series, New York, p. 155-169, 1993.

MORILHAS, Leandro José et al. Spin-off e a criação de valor para os acionistas: um estudo de caso da Motorola. In: SEMEAD, 12, 2009. São Paulo.

MOTTA, Fernando C. Prestes. Teoria geral da Administração. 7. ed. São Paulo: Pioneira, 1979. $213 p$.

OECD. Oslo Manual. European Comission, 1990.

OLIVEIRA, Nélio. Organizações automatizadas. Rio de Janeiro: LTC, 2007. 208p.

OSTERWALDER, Alexander; PIGNEUR, Yves. Business Model Generation. Rio de Janeiro: Alta Books, 2011. 280p.

OSTERWALDER, Alexander; PIGNEUR, Yves; TUCCl, Christopher L. Clarifying business models: origins, present, and future of the concept. Communications of Association for Information Systems. Atlanta, v. 15, may 2005.

PICCHIAl, Djair. Estruturas organizacionais modelos. Universidade Federal de São Paulo. 2010. Disponível em: http://dgi.unifesp.br/seplan/ templates/docs/seplan-modelos_de_estruturas_ organizacionais_material.pdf. Acesso em: 23 jun. 2012. 


\section{REFERÊNCIAS}

RESENDE, Alexandre Pimentel de et al. Consórcio modular: o novo paradigma do modelo de produção. In: ENCONTRO NACIONAL DE ENGENHARIA DE PRODUÇÃO. 22., 2002. Anais [...]. Curitiba: Associação Brasileira de Engenharia de Produção, outubro 2002.

RIBEIRO, Denise de Andrade. Estruturas organizacionais: um possível delineamento da produção científica nacional sobre o tema no período 1998-2008. Revista Eletrônica Gestão e Sociedade. Minas Gerais, v. 3, n. 6, jul./dez. 2009.

ROBBINS, Stephen Paul. Administração mudanças e perspectivas. São Paulo: Saraiva, 2000. 524p.

SACOMANO NETO, Mário; ESCRIVÃO FILHO, Edmundo. Estrutura organizacional e equipes de trabalho: estudo da mudança organizacional em quarto grandes empresas industriais. Gestão e Produção. v.7, n.3, p.136-145, Agosto 2000.

SILVA, Reinaldo O. da. Teorias da Administração. São Paulo: Pioneira Thomson Learning, 2001. 523p.

URBANAVICIUS JÚNIOR, Vladas. Parâmetros organizacionais de Mintzberg: análise da estrutura organizacional de um programa interinstitucional de pré-incubação de empresas no município de Itajubá, MG. 2008. 138 f. Dissertação (Mestrado em Administração) - Faculdade de Ciências Administrativas, Universidade Metodista de São Paulo, São Bernardo do Campo, 2008.
VASCONCELLOS, Eduardo; HEMSLEY, James R. Estrutura das organizações. 3. ed. São Paulo: Pioneira, 1997. 208p.

YIN, Robert K. Estudo de caso. 4. ed. Porto Alegre: Bookman, 2010. 248p.

\section{José Turíbio Oliveira ${ }^{1}$}

Doutor em Administração pela USCS (Capes 5). Mestre em Administração pela UMESP. Professor de Administração na USCS. Professor de Administração na Fundação Santo André. Professor de Pós-Graduação na FIA. Universidade Municipal de São Caetano do Sul. Centro Universitário Fundação Santo André. Fundação Instituto de Administração. E-mail: turibiooliveira@uol.com.br

\section{Sérgio Feliciano Crispim²}

Livre Docente em Marketing pela USP. Pós-Doutor em Administração pela FEA-USP. Doutor em Administração pela FEAUSP. Mestre em Administração pela FEA-USP. Professor da EACH-USP. Professor do programa de Mestrado e Doutorado da Universidade Municipal de São Caetano do Sul. E-mail: scrispim@uol.com.br

Data da Submissão: 21/10/2018

Data de Aceite: 19/09/2019 